\title{
Some Empirical Perspectives on Foreign Language Learning in Sudan
}

\author{
Adil Ishag \\ Faculty of Education, International University of Africa, Sudan \\ E-mail: adil.ishag@gmail.com
}

Received: 15-12-2016

Accepted: 17-02-2017

Published: 01-07-2017 doi:10.7575/aiac.ijalel.v.6n.4p.137

Advance Access Published: April 2017

URL: http://dx.doi.org/10.7575/aiac.ijalel.v.6n.4p.137

\begin{abstract}
This study attempted to provide a general view of the situation and perspective on foreign language learning and teaching at the tertiary level in Sudan, with special focus on English and German. It further explored motivation and reasons for majoring in English and German among Sudanese students and the level of satisfaction in studying theses languages as major disciplines. Additionally, students' knowledge of foreign languages and their preferences for learning certain foreign languages have been reported. In order to achieve the objective of this study, a questionnaire was administered to a sample composed of 148 students majoring in English and 73 Students majoring in German, at the University of Khartoum. The obtained results revealed that Sudanese students in both departments were highly satisfied in majoring in English and German, however students were majoring in English mostly due to personal interest, while there were more students majoring in German due to entry requirement than those in the English department. Furthermore, students have shown varying degrees of interest in learning other languages such as Chinese, Spanish, French and Italian. Finally, based on the findings of the study, a number of proposals have been made, which might contribute to the improvement of foreign language learning and teaching in Sudan.
\end{abstract}

Keywords: Foreign Language, English, German, Language Learning, Language Acquisition.

\section{Introduction}

In our globalized world, knowledge of foreign languages has become increasingly important for individuals and institutions alike. Language functions as a learning tool and a means of communication between different cultural groups, and enhances mutual understanding and appreciation of other cultures. However, learning a foreign language is socially constructed and as such is also partly conditioned by the social environment and practices (Ushioda, 2008). Moreover, As Lantolf and Thorne (2006) point out that current linguistic theorists are showing more and more interest in the socio-cultural perspective of second language learning and research, taking into account the social, cultural, and historical contextual dimensions of language.

The process of foreign language learning is multifaceted involving individual, socio-cultural and psychological factors such as motivation and attitudes towards the language and language speaking community and culture. Nevertheless, "Motivation is not located solely within the individual but is socially distributed and created within cultural systems of activities involving the mediation of others" (Rueda \& Moll, 1994). These viewpoints are in accordance with Gardner's (1996) view that learning motivation is a learner internal attribute, but can be influenced by external factors.

On the other hand, learning a foreign language goes far beyond learning linguistic knowledge, to involve personal and cultural dimension, which as Byram (1989) stated, this points to the importance of culture learning in second and foreign language. This implies that language is the carrier of culture and culture is embedded in language and thus incorporating target language culture into language learning curriculum is assumed to facilitate and contribute to the target foreign language learning. In this regards, Williams (2004) postulated that "learning a foreign language involves far more than simply learning skills, or a system of rules, or a grammar; it involves an alteration in self-image, the adoption of new social and cultural behaviors and ways of being, and therefore has a significant impact on the social nature of the learner. Hence, foreign language teaching and learning should be contextualized within these personal and cultural dimensions to have a comprehensive overview.

In a time of big changes at the political and educational level in Sudan, since the beginning of 1990s, this paper tries to examine the status and perspectives of foreign language learning under the era of Arabicization at Sudanese universities, where Arabic became the medium of instruction instead of English. Accordingly, the current study attempts to provide a comprehensive overview of the current situation and future perspective of foreign language learning and teaching in Sudan, with special reference to the tertiary level in general and English and German language in particular. It also tries to investigate the reasons of studying and majoring in English and German respectively, and to which extent students are satisfied in studying these languages. In addition, Students' knowledge of foreign languages and their preferences for learning certain foreign languages will be reported. 


\section{Methodology of Investigation}

For carrying out the current study the quantitative approach was used, by constructing and developing a structured questionnaire to collect the required data. The sample of the study composed of undergraduate students majoring in English and German language respectively in the Faculty of Arts, University of Khartoum during the academic year 2013-2014. Participants were selected according to the convenient sampling procedure; nevertheless the two samples were not evenly represented in terms of gender and department, because most of the students were females and thus it was not possible to equalize the gender selection. On the other hand, there were also considerably fewer students majoring in German compared to students majoring in English language. However, the study was highly representative for the German department; this was due to the fact that 73 students out of 79 students majoring in German have participated in the survey (see Table 2.1).

Table 2.1 Demographic Background of the Participants

\begin{tabular}{lccc}
\hline Department/ Gender & Male & Female & Total \\
\hline English & 35 & 113 & 148 \\
German & 18 & 55 & 73 \\
Total & 53 & 168 & 221 \\
\hline
\end{tabular}

After obtaining permission for conducting the study and finalizing all relevant formalities; the questionnaires were administered at the end or in between lectures. First, participants were ensured about the confidentiality and anonymity of the research survey, which would solely be used for scientific purposes. They were also informed that are no right or wrong answers and thus they might choose the responses that suitably reflect their actual opinions. The questionnaire contained first demographic variables such as gender and department, followed by structured questions pertaining to the research questions and objectives.

\section{Results and Discussion}

The obtained data were thoroughly coded, tabulated and entered into SPSS spreadsheet, and then descriptively and statistically analyzed. The results are presented and interpreted in the following tables.

Table 3.1 Students' reasons for specializing in the intended language

\begin{tabular}{lllllll}
\hline Reason & $\begin{array}{l}\text { Personal } \\
\text { Interest }\end{array}$ & $\begin{array}{l}\text { Familial } \\
\text { Interest }\end{array}$ & $\begin{array}{l}\text { Admission } \\
\text { Grades }\end{array}$ & Prestige & Other & Total \\
\hline English & $87.8 \%$ & $2.7 \%$ & $7.4 \%$ & $2.0 \%$ & $0.1 \%$ & $100 \%$ \\
German & $43.8 \%$ & $6.8 \%$ & $30.2 \%$ & $4.1 \%$ & $15.1 \%$ & $100 \%$ \\
\hline
\end{tabular}

Students were asked about their reasons and justifications of majoring in the target foreign language. As shown in the table above (Table 3.1), it was clear that students have majored in English language due to personal motivation and interest in the language with $87.8 \%$, which surpassed the other reasons. This result is not surprising in the era of globalization where English is the most widely studied foreign language and it is generally considered as a global language. Additionally, Sudan is an Anglophone country and thus a command or degree in English would considerably offer more work and career opportunities. On the other hand, students have majored in German due to personal motivation $43.8 \%$, followed by grades $30.2 \%$ which is 4 times more than for students majoring in English. This indicates that those students have majored in German because of their overall academic grades, which is the only criterion for university admission in Sudan. Thus, students might study a discipline other than their preferred one due to their lower achieved grades. Nevertheless, Students mentioned prestige for studying German $4.1 \%$ compared with only $2.0 \%$, this might be explained in terms of the uniqueness of the German language in Sudan, while every educated people knows English and it is a compulsory subject at schools and even at the university regardless of the specialization. In this context, mastering and studying a relatively sophisticated and not new introduced language like German, would offer some degree of prestige in the Sudanese community. In this regard, Mugddam (2010), found that $25 \%$ of the students majoring in different foreign languages learn French for prestige reasons, followed by English $18.1 \%$ and German $8 \%$. However, no one has indicated learning Chinese for prestige, and only $0.6 \%$ indicated that they need Chinese for communicating with the world outside.

Table 3.2 Level of satisfaction in joining the English or German department

\begin{tabular}{|c|c|c|c|c|c|c|}
\hline \multicolumn{7}{|c|}{ Responses } \\
\hline Department & Very Satisfied & Satisfied & Undecided & Not Satisfied & $\begin{array}{l}\text { Stongly } \\
\text { Dissatisfied }\end{array}$ & Total \\
\hline English & $58.1 \%$ & $24.3 \%$ & 8.15 & $6.1 \%$ & 3.45 & $100 \%$ \\
\hline German & $37.0 \%$ & $50.7 \%$ & $8.2 \%$ & $2.7 \%$ & $1.4 \%$ & $100 \%$ \\
\hline
\end{tabular}


Students are also asked to indicate to which degree they were satisfied about their decision in joining the respective department and selecting the specialization. The results above in (table 3.2) showed that 58.1\% of students majoring in English were very satisfied about specializing in English, compared to $37.0 \%$ of students specializing in German language. However, there were no significant differences when we compare the whole table between the two departments. On the other hand, there were fewer students who were not satisfied about joining the English or the German programs at the University. One might conclude that students in both departments were generally highly satisfied in majoring in either English or German at the university. This result implies that studying foreign languages are highly appreciated and regarded among Sudanese, at least in comparison to other related fields in humanities and social sciences. Although, Arabicization policy in Sudan is assumed to have a negative impact on foreign languages in general and English in particular, Sudanese students have still reflected positive tendency toward learning foreign languages.

Table 3.3 Choosing another field of study

\begin{tabular}{lllll}
\hline \multicolumn{5}{c}{ Responses } \\
\hline Department & Yes & No & Undecided & Total \\
English & $16.9 \%$ & $76.4 \%$ & $6.7 \%$ & $100 \%$ \\
German & $37.0 \%$ & $49.3 \%$ & $13.7 \%$ & $100 \%$ \\
\hline
\end{tabular}

Similarly, students were also asked about their wish to study another discipline instead of the current major, if it were up to them or would have the possibility to do so. The result as shown in (table 3.3 ) revealed that $76.4 \%$ of the students in the English department negatively responded, which means that English was their optimal first choice. This finding could be interpreted again in the light of the previous result (in Table 3.1) which showed that students have mainly majored in English language based upon their personal motivation and interest. On the other hand, only $49.3 \%$ of students majoring in German have negatively responded, which means that they wish to change their discipline if it were up to them. Additionally, as shown in the table above (3.3) about the students who positively responded or were undecided, this result was further supported in favor of the English department.

Table 3.4 Second specialization of the participants

\begin{tabular}{lccccccccc}
\hline \multicolumn{8}{c}{ Second Major } \\
\hline Department & French & Linguistics & Chinese & Arabic & German & Russian & English & Missing & Total \\
English & $39.2 \%$ & $32.4 \%$ & $19.6 \%$ & $4.0 \%$ & $3.4 \%$ & $1.4 \%$ & - & $0.0 \%$ & $100 \%$ \\
German & - & $32.9 \%$ & - & $12.3 \%$ & - & - & $45.2 \%$ & $9.6 \%$ & $100 \%$ \\
\hline
\end{tabular}

As shown in the table (3.4), 39.2\% of the students in the English department have chosen French as a second major, followed by linguistics $32.4 \%$ and Chinese with $19.6 \%$, while $4.0 \%$ chosen Arabic, 3.4\% German and $1.4 \%$ Russian. Concerning the German department, 45.2\% were second majoring in English, 32.9\% in Linguistics, followed by Arabic $12.3 \%$ and $9.6 \%$ did not disclose their second major. So, French was the most preferred choice for the students of English language, while students in the German department have preferred English as a second major. This reflects the importance and utilitarian use of English language as an international language among Sudanese and as a prerequisite for better job opportunities. Additionally, it might be concluded that linguistics was a preferred discipline in both departments, whereas French and Chinese were considerably preferred among students majoring in English. The other languages, however, have a lesser degree of popularity.

Table 3.5 Students' knowledge of foreign languages

\begin{tabular}{ll}
\hline English Department & German Department \\
\hline French $29.4 \%$ & English $83.7 \%$ \\
Chinese $14.9 \%$ & French $5.5 \%$ \\
Russian $11.8 \%$ & Turkish $3.6 \%$ \\
German $8.8 \%$ & Chinese $1.8 \%$ \\
Turkish $8.8 \%$ & Spanish $1.8 \%$ \\
Spanish $5.9 \%$ & Nubian $1.8 \%$ (a Sudanese language) \\
Fur $5.9 \%$ (a Sudanese language) & Zagawa $1.8 \%$ (a Sudanese language) \\
Hungarian $2.9 \%$ & - \\
Hindi $2.9 \%$ & - \\
Hausa $2.9 \%$ (also spoken in Sudan) & - \\
Nubian $2.9 \%$ (a Sudanese language) & - \\
Nuer $2.9 \%$ (a south Sudanese language) & - \\
\hline
\end{tabular}


Students were asked about their language knowledge and which languages they could already speak or have a command of. As shown in the table above (table 3.5), the results are partially consistent with the findings of the second major of the students in regard to French and Chinese especially. Thus, in the English department, 29.4\% of the students have a command in French, 14.9\% in Chinese 14, 11.8\% in Russian, 8.8\% in German, $8.8 \%$ in Turkish and 5.9\% in Spanish. By contrast, $83.7 \%$ of the students in the Germen department stated having a command in English which was their second major and almost all Sudanese students are supposed to have a varying degree of knowledge in English at least theoretically, since it is a obligatory subject at schools and a requirement subject at Sudanese universities. 5.5\% have knowledge of French, 3.6\% could speak Turkish, 1.8\% can speak Chinese, and 1.8\% Spanish. Furthermore, 2.9\% of the students in the English department could speak Hungarian and Hausa as well.

In both departments, there were some students who clearly indicated their knowledge of some Sudanese languages such as Fur which is a western Sudanese language mainly spoken in Darfur region, and other Sudanese languages such as Nubian, Nuer, and Zagawa which is also a western Sudanese language. Studying or learning a Sudanese language as a second or foreign language is actually not common at least among educated people and would mostly be regarded as vernacular languages. However, the interest in learning a certain Sudanese vernacular language other than Sudanese Arabic; may indicate some identification and affiliation instances within a particular ethnic group.

Table 3.6 Students' preferences of foreign languages

\begin{tabular}{ll}
\hline English Department & German Department \\
\hline Spanish $23.5 \%$ & French $33.3 \%$ \\
Chinese $19.6 \%$ & Chinese $20.2 \%$ \\
French $18.6 \%$ & Spanish $19.2 \%$ \\
Italian $10.8 \%$ & English $10.1 \%$ \\
German $7.8 \%$ & Italian $5.1 \%$ \\
Russian $4.9 \%$ & Russian $3 \%$ \\
Turkish $3.9 \%$ & Japanese $2 \%$ \\
Hindi $3.9 \%$ & Korean $2 \%$ \\
Japanese $1.5 \%$ & Turkish $1 \%$ \\
Persian $1 \%$ & Swahili $1 \%$ \\
Greek $1 \%$ & Ukrainian $1 \%$ \\
Swahili $1 \%$ & Latin $1 \%$ \\
Latin $0.5 \%$ & Hausa $1 \%$ \\
Korean $0.5 \%$ & - \\
Hebrew $0.5 \%$ & - \\
Kurdish $0.5 \%$ & - \\
Dinka $0.5 \%$ (a south Sudanese language) & - \\
Shilluk $0.5 \%$ (a south Sudanese language) & - \\
\hline
\end{tabular}

The responses to the question which languages the participants wish to learn if they have the opportunity to do so, the findings as in the table above (table 3.6) revealed that $23.5 \%$ of the students in the English department would firstly like to learn Spanish; in the second place 19.6\% would like to learn Chinese; in the third place18.6\% like to learn French; in the fourth place $10.8 \%$ would like to learn Italian; in the fifth place $7.8 \%$ like to learn German; followed by those who wish to learn Russian $4.9 \%$, Turkish $3.9 \%$, and Hindi $3.9 \%$ as well as other languages to a lesser degree such as Japanese, Swahili, Latin, Korean, Persian, Hebrew, Kurdish and the two south Sudanese languages, namely Dinka and Shilluk.

On the other hand, $33.3 \%$ of the students in the German department would like to learn French in the first place; secondly $20.2 \%$ like to learn Chinese; thirdly $19.2 \%$ would like to learn Spanish; fourthly $10.1 \%$ like to learn or accurately maybe to improve their English; fourthly 5.1\% like to learn Italian and 3\% would like to learn Russian. In addition to other languages with a lesser degree such as Japanese, Korean, Turkish, Swahili, Ukrainian, Latin and Hausa which is widely spoken in some regions in Sudan.

The findings clearly indicate the interest of Sudanese students in learning Spanish especially among students of the English department which has been placed first and in the German department was a third choice after French and Chinese. Surprisingly, Chinese was the second choice for students in both departments with $19.6 \%$ and $20.2 \%$ respectively. This result is in line with $\mathrm{Wu}$ (2010) who stated that "there is reportedly a growing demand for learning Chinese among university students in North America". 
The increasing interest in learning Chinese despite its difficulty is due to the substantial role of China nowadays as an economic leading power worldwide in general and its evident investments in Sudan in the oil other sectors, which created a lot of employment opportunities. Thus, having command in Chinese will facilitate getting a well-paid job; there are even some students who got jobs even before finishing their studies, due to the increasing demand for those who could communicate in Chinese. Moreover, a lot of scholarships, short training courses in china are offered to Sudanese students, which attract a lot of students to study or learn Chinese. In this regard, Mugaddam (2010) found that Chinese was second after English in Sudan in terms of learning the language for job opportunities and employment reasons, where English came first as a useful language for getting a job with $33.1 \%$; followed by Chinese $23.1 \%$; German 14.7\%; and French 7.5\%.

Sudanese students showed also a special interest in the Italian language, although there is no any department for teaching Italian or Spanish at all Sudanese universities. The interest in Spanish might be reasonable due to the status of Spanish language as the second most widely spoken native language and its special status in the united states nowadays, and this in turn might explain why the students of the English department preferred firstly to learn Spanish, which is the second most spoken language after English in the united states. However, the interest in the Italian language which came before the German language might rely in the common perception of the Italian language as a prestigious beautiful language regardless of its utility in Sudan or even worldwide.

\section{Conclusions and Implications}

The current study aimed at investigating the status, degree of satisfaction and reasons of learning foreign languages among Sudanese university students, in addition to students' knowledge of languages and their preferences for learning foreign languages. The findings revealed that students in both departments were generally satisfied to major in English or German, however there were more students who majored in German due to their obtained grades as an entry requirement for university admission compared to students who mainly majored in English because of their personal interest. This higher degree of satisfaction in studying a foreign language could be explained in the light of the status of foreign languages departments within the humanities and social sciences in Sudan, where students at the faculty of Arts would mostly prefer studying a foreign language as a first choice and after that search for studying other disciplines, if they could not meet the admission requirement in the intended foreign language department.

Apart from English and German; French, English and Chinese were widely chosen as a second major by the respondents. Participants had knowledge of some foreign language with varying degrees of popularity such as: English, French, Chinese, German, Russian, Turkish and Spanish. It is worth mentioning that English language programs are almost offered at all Sudanese universities, mostly affiliated to the Faculty of Arts and the Faculty of Education, followed by French in some four universities, German is offered at two universities, while Russian and Chinese are only offered at the University of Khartoum. However, international languages such as Spanish and Italian have never been yet offered by Sudanese Universities.

Based on the findings, it could be concluded that Sudanese students are highly motivated and interested in learning foreign languages for different reasons. The employment opportunities and economic factors play major role in learning some languages such as Chinese and to some degree English and German as an influential economic and industrial power. This implies the instrumentality in learning the target foreign language among Sudanese, especially in the current socio-economic situation of the country, where there are many international organizations in different areas throughout the country, which necessitate employees with command in working international foreign languages. However, there are still considerable number of students who mostly learn foreign languages for the sake of the language and language speaking community as in the case of the Italian language.

However, the outcomes of the study are not exhaustive and comprehensive justifications for learning foreign languages. There are evidently other justifications and rationales for studying or learning a foreign language in addition to those mentioned in the current study. Moreover, the sample participated in this study were university students studying foreign languages as a major discipline and thus another group of Sudanese learners would might have indicated quite different rationales for learning foreign languages. In this context, as Seliger \& Shohamy (1997) pointed out that "qualitative research is usually complex in design and broad in scope", thus the quantitative data collection used might have limited the responses to those questions imposed upon the respondents and as such a qualitative data collection approach is also recommended for carrying out further similar studies in Sudan.

Nevertheless, the findings of the current study could ultimately be used as a starting-point for further studies and pedagogical debates, which take into account the socio-cultural factors that might influence the predisposition of students in learning certain foreign languages. Moreover, it is also recommended to investigate the role of socioeconomic factors and gender on students' preferences and reasons for majoring or studying a foreign language. The findings might also be of a significant importance to Sudanese higher institutions to consider the needs of students, and accordingly offering and establishing new departments for world foreign languages such as Spanish and Italian, which were indicated by the participants' interest and tendency to learn these languages.

\section{References}

Byram, M.(1989). Cultural Studies in Foreign Language Education. Clevedon, PA: Multilingual Matters Ltd.

Gardner, R.C. (1996). Motivation and Second Language Acquisition: Perspectives. Journal of the CAAL, 18(2), 19-42. 
Mugddam, A. (2012). Foreign Language Teaching in Sudanese Universities: Goals, Attitudes and Reality. Indonesian Journal of Applied Linguistics, Vol. 2 (1), pp. 130-138.

Lantolf, J. P. \& Thorne, S.L. (2006). Sociocultural Theory and the Tenesis of Second Language Development. Oxford: Oxford University Press.

Rueda. R. \& Moll, I. (1994). A Sociocultural Perspective on motivation. In H.F. O’Neil, Jr. and M. Drillings (Eds.), Motivation: Theory and Research, pp. 117-137. Hillsdale, N.J.: Lawrence Erlbaum.

Seliger, H.W. \& Shohamy, E (1997). Second Language Research Methods. Oxford: Oxford University Press.

Ushioda, E. (2008). Motivation and Good Language Learners. In C. Griffiths (Ed.), Lessons from Good Language Learners, pp. 19-34. Cambridge: Cambridge University Press.

Williams, M. (1994). Motivation in Foreign and Second Language Learning: An Interactive Perspective. Educational and Child Psychology, 11, 77-84.

Wu, J. (2010). Chinese Class Enrolments are Soaring South of The Border: What Can Canadian Language Educators Do? Notos/Second Language \& Intercultural Council, 10 (1), 54-7. 